in vivo $34: 3565-3572(2020)$

doi:10.21873/invivo.12200

\title{
CT Derived Muscle Measures, Inflammation, and Frailty in a Cohort of Older Cancer Patients
}

\author{
MAGNUS HARNESHAUG ${ }^{1,2}$, JURATE SALTYTE BENTH ${ }^{1,3,4}$, LENE KIRKHUS $^{1,2,5}$, \\ BJORN HENNING GRONBERG ${ }^{6,7}$, SVERRE BERGH $^{1,8}$, SIRI ROSTOFT $^{2,9}$ and MARIT SLAAEN ${ }^{1,2,10}$ \\ ${ }^{1}$ The Research Centre for Age Related Functional Decline and Diseases, \\ Innlandet Hospital Trust, Ottestad, Norway; \\ ${ }^{2}$ Institute of Clinical Medicine, Faculty of Medicine, University of Oslo, Oslo, Norway; \\ ${ }^{3}$ Institute of Clinical Medicine, Campus Ahus, University of Oslo, Oslo, Norway; \\ ${ }^{4}$ Health Services Research Unit, Akershus University Hospital, Nordbyhagen, Norway; \\ ${ }^{5}$ Department of oncology, Oslo University Hospital, Oslo, Norway; \\ ${ }^{6}$ Department of Oncology, St. Olav's Hospital, Trondheim University Hospital, Trondheim, Norway; \\ ${ }^{7}$ Department of Clinical and Molecular Medicine, NTNU, \\ Norwegian University of Science and Technology, Trondheim, Norway; \\ ${ }^{8}$ Norwegian Advisory Unit on Aging and Health, Vestfold Hospital Trust, Tфnsberg, Norway; \\ ${ }^{9}$ Department of Geriatric Medicine, Oslo University Hospital, Oslo, Norway; \\ ${ }^{10}$ The Cancer Unit, Innlandet Hospital Trust, Hamar Hospital, Hamar, Norway
}

\begin{abstract}
Background/Aim: Muscle loss, inflammation, and frailty are prevalent among older cancer patients. We aimed to evaluate whether inflammatory markers could identify muscle loss, and if muscle measures differed between frail and non-frail patients. Patients and Methods: A total of 115 patients $\geq 70$ years old with solid tumors were included. Inflammation was measured using the Glasgow Prognostic Score (GPS), which is based on C-reactive protein (CRP) and albumin levels, and CRP alone. Frailty was evaluated using a modified geriatric assessment ( $m G A$ ) of eight domains affecting older patients' health status. Computed tomography-derived muscle measures were collected at the level of the third lumbar vertebra. Results: Patients with $G P S=2$ and $C R P>27 \mathrm{mg} / \mathrm{l}$ exhibited poorer muscle measures compared to patients with lower levels. No associations between mGA-based frailty and muscle mass were found. Conclusion: Inflammation has detrimental effects on muscle
\end{abstract}

This article is freely accessible online.

Correspondence to: Magnus Harneshaug, The Research Centre for Age-related Functional Decline and Diseases, Innlandet Hospital Trust, Innlandet Hospital Trust, P.O. Box 68, 2313 Ottestad, Norway and the Institute of Clinical Medicine, Faculty of Medicine, University of Oslo, Oslo, Norway. Tel: +47 91579145, e-mail: Magnus.Harneshaug@sykehuset-innlandet.no; MagnusHarneshaug@ gmail.com

Key Words: Biomarkers, frailty, muscle loss, older cancer patients. mass. However, GPS or CRP alone cannot be used to identify muscle loss, and muscle measures were not associated with frailty in this series.

Muscle loss is commonly seen in both cancer and aging. Although part of the normal aging process (1), it may be accelerated by several factors, such as poor diet, sedentary lifestyle, drug treatments, chronic diseases, and cancer (2). Loss of muscle mass negatively affects patient health, resulting in impaired mobility, loss of independence, increased risks of falls and fractures, impaired activities of daily living (ADL), and increased risk of death $(3,4)$. Among cancer patients, muscle loss is also associated with chemotherapy toxicity, surgical complications, and mortality $(5,6)$.

Chronic inflammation is believed to play a role in both agerelated and cancer-related muscle loss. An association between chronic inflammation and loss of muscle mass, strength and function have been reported in several observational studies of older adults $(7,8)$, and similar associations have been observed in cancer patients (9). Furthermore, muscle loss is one of the diagnostic criteria for cancer cachexia (10), which is perceived as being related to systemic inflammation (11). Inflammation is closely associated with aging and is believed to be a mechanism behind several age-related diseases, such as dementia, cardiovascular disease, and depression (12). Moreover, inflammation is thought to be involved in the development of frailty, which is a multidimensional syndrome characterized by "extreme vulnerability to endogenous and exogenous stressors exposing the individual to a higher risk 
Table I. Modified geriatric assessment domains and tools.

\begin{tabular}{|c|c|c|c|c|}
\hline Domain & $\begin{array}{l}\text { Assessment } \\
\text { method }\end{array}$ & Range & Rated by & Cut-off value for frailty \\
\hline $\begin{array}{l}\text { Nutritional } \\
\text { status }\end{array}$ & PG-SGA & & Nurse/patient & $\begin{array}{l}\text { Considered severely malnourished by the } \\
\text { nurse or self-reported weight loss of } \geq 10 \% \\
\text { during last } 6 \text { months. }\end{array}$ \\
\hline Comorbidities & OARS & $\begin{array}{l}0-15 \text { (higher scores indicate } \\
\text { more comorbidities) }\end{array}$ & Patient & $>3$ points \\
\hline $\begin{array}{l}\text { Medications, } \\
\text { polypharmacy }\end{array}$ & ATC & $0-13$ & Nurse/physician & $\begin{array}{l}>7 \text { regular medications (excluding ointments } \\
\& \text { common vitamins) }\end{array}$ \\
\hline Falls & & & Nurse & $\begin{array}{l}\text { Patient reported } \geq 2 \text { falls during the last } 6 \\
\text { months }\end{array}$ \\
\hline $\begin{array}{l}\text { Activities of } \\
\text { daily living }\end{array}$ & EORTC QLQ-C30 Q5 & & Patient & $\begin{array}{l}\text { Responses to question } 5 \text { of "yes a little", } \\
\text { "quite a bit", or "very much" }\end{array}$ \\
\hline $\begin{array}{l}\text { Depressive } \\
\text { symptoms }\end{array}$ & GDS-15 & $\begin{array}{l}\text { 0-15 (higher scores indicate } \\
\text { more symptoms) }\end{array}$ & Patient & $\geq 7$ points \\
\hline $\begin{array}{l}\text { Physical } \\
\text { function }\end{array}$ & TUG & & Nurse & $>14 \mathrm{~s}$ \\
\hline $\begin{array}{l}\text { Cognitive } \\
\text { function }\end{array}$ & MMSE & $\begin{array}{l}\text { 0-30 (higher scores indicate } \\
\text { better function) }\end{array}$ & Nurse & $<24$ points \\
\hline
\end{tabular}

PG-SGA: Patient-generated Subjective Global Assessment; OARS: The Physical Health Section of the Older Americans' Resources and Services Questionnaire; ATC: Anatomical Therapeutic Chemical Classification System; EORTC QLQ-C30 Q5: The European Organization for Research and Treatment of Cancer Quality of Life Core Questionnaire; GDS-15: Geriatric Depression Scale; TUG: timed up and go test; MMSE: Norwegian Revised Mini Mental State Examination.

of negative health-related outcomes" (13), and is regarded as closely related to muscle loss (14).

We have previously shown that inflammation, measured by the Glasgow prognostic score (GPS), was associated with frailty in older adults with cancer (15). Given the presumably close inter-relatedness of frailty, inflammation, and muscle loss, we aimed to determine whether routinely measured biomarkers of inflammation may identify muscle loss in older patients with cancer, and whether frailty is associated to computed tomography (CT)-derived muscle measures in these patients.

\section{Patients and Methods}

This cross-sectional study evaluated prospectively collected data from a large multi-center study that recruited patients between January 2013 and April 2015 from the outpatient cancer clinics of two university hospitals and six local hospitals in southeast Norway. The inclusion criteria were age of $\geq 70$ years, histologically or cytologically verified solid malignant tumors, and referral to an outpatient oncology service because of a new cancer diagnosis or the first relapse after potentially curative cancer treatment. Patients were followed for two years or until death. The study's protocol was approved by the Regional Committee for Medical and Health Research Ethics, South East Norway (2012/104) and was registered at clinicaltrials.gov (NCT01742442). All patients provided written informed consent before their participation.

Assessments. Baseline assessments were carried out before treatment commenced and included clinical and demographic data, a modified
Geriatric Assessment (mGA), blood sampling, Eastern Cooperative Oncology Group (ECOG) performance status, cancer type and stage, location of metastasis, and whether the treatment intent was curative or palliative. Body composition was assessed from diagnostic CT scans performed within 31 days before or after the inclusion date.

To identify frail patients, we used a GA, which is referred to as modified (mGA) since it does not fulfill all criteria of a comprehensive GA (16). We assessed eight different domains; comorbidity, activities of daily living (ADL), depression, falls, polypharmacy, cognitive- and physical function, and nutritional status (Table I). Our frailty classification was based on a modification of the Balducci criteria (17). The criterion of $>85$ years was excluded, as the original report indicated that this criterion was not absolutely required (17). Further, we added polypharmacy to the assessment, based on the proposal by Winograd et al. (18), and the timed up and go test (TUG), as it is reportedly a sensitive and specific measure of frailty (19). Thus, based on the Balducci criteria, frailty was identified if one or more of the following criteria were fulfilled: dependencies in ADL, significant comorbidity, polypharmacy, or any of the geriatric syndromes (e.g., impaired cognitive function, depression, malnutrition, or falls).

Inflammation was assessed by C-reactive protein (CRP) and the Glasgow Prognostic Score (GPS). Blood samples were collected at the time of inclusion, and the CRP results were categorized into quartiles. The GPS is an inflammation-based prognostic scoring system, which has been validated in $>60$ studies to predict survival, weight loss, and muscle loss in cancer patients (20). Higher scores indicate greater systemic inflammation, with the scores being 0 points (CRP of $\leq 10 \mathrm{mg} / \mathrm{l}$ and albumin of $\geq 35 \mathrm{~g} / \mathrm{l}$ ), 1 point (CRP of 


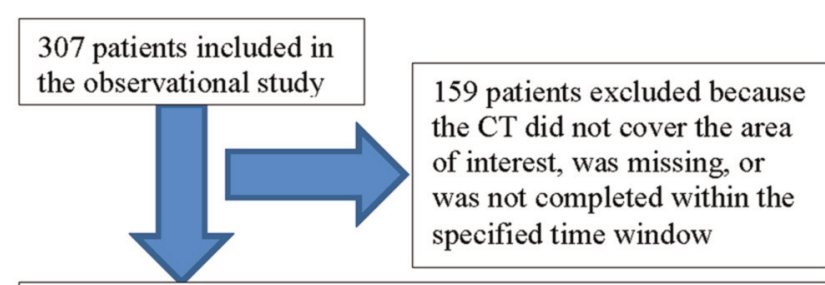

148 patients with CT scans within the specified time window

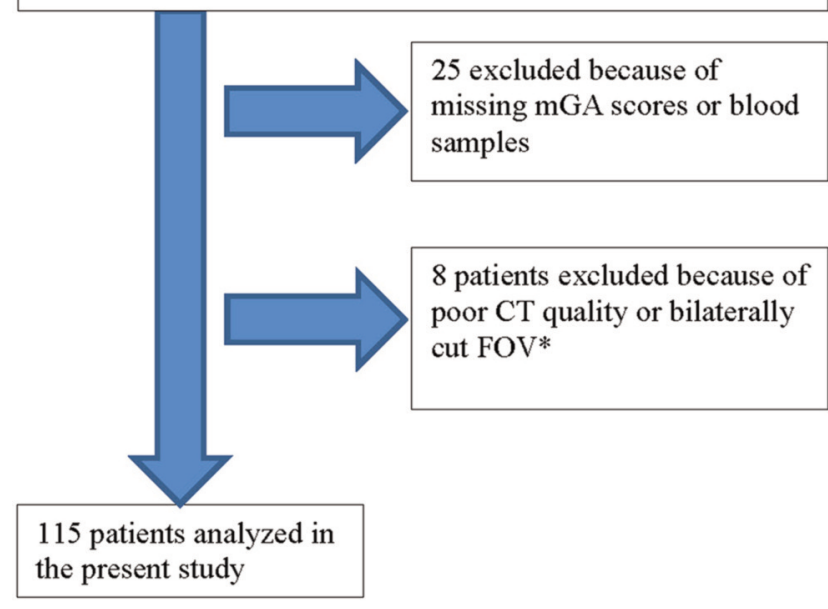

Figure 1. Study flowchart. CT: Computed tomography; mGA: modified geriatric assessment; FOV: field of view.

$>10 \mathrm{mg} / \mathrm{l}$ or albumin of $<35 \mathrm{~g} / \mathrm{l}$ ), or 2 points (CRP of $>10 \mathrm{mg} / \mathrm{l}$ and albumin of $<35 \mathrm{~g} / \mathrm{l}$ ).

Diagnostic CT scans performed within 31 days before or after the inclusion date were used for body composition analyses. Single slices at the level of the third lumbar vertebra (L3) were analyzed by a single trained observer using Slice-O-Matic software (version 5.0; Tomovision, Montreal, Canada). The total cross-sectional area of skeletal muscle $\left(\mathrm{cm}^{2}\right)$ at this level is strongly correlated to the whole-body skeletal muscle mass (21). We used pre-established Hounsfield Unit (HU) thresholds for the demarcation of skeletal muscle ( -29 to $150 \mathrm{HU})$, visceral adipose tissue $(-150$ to $-50 \mathrm{HU})$, and subcutaneous and intermuscular adipose tissue $(-190$ to -30 $\mathrm{HU}$ ). The skeletal muscle index (SMI, $\mathrm{cm}^{2} / \mathrm{m}^{2}$ ) was calculated by dividing the muscle area by height squared $\left(\mathrm{m}^{2}\right)$. The skeletal muscle density (SMD, expressed as mean HU) was reported for the whole muscle area at the L3 level. SMD decreases when fat accumulates in the muscles. Thus, SMD is considered an indirect measure of muscle quality (22).

Statistics. The relationship between the muscle measures (SMD and SMI) and the inflammation markers (CRP and GPS) was estimated using bivariate and multiple linear regression models for hierarchical data. For each of the two muscle measures, we applied three models assessing the association between the SMD/SMI and GPS scores (Model 1), between the SMD/SMI and CRP (Model 2), and between the SMD/SMI and frailty (Model 3). All multiple linear regression models were adjusted for age, sex, diagnosis, disease stage, use of anti-inflammatory drugs, and body mass index (BMI).
The models included study center as a random effect to adjust the estimates for possible intra-center correlations. Due to non-linear association between the muscle measures and CRP, the CRP values were categorized into quartiles. All statistical analyses were performed using IBM SPSS software (version 25) and SAS software (version 9.4). Results with $p$-values below 0.05 were considered statistically significant.

\section{Results}

Among the 307 patients in the original cohort, 148 patients had CT scans that covered the 3rd lumbar level, performed within 31 days from the inclusion date. We excluded eight patients due to poor-quality scans or scans that did not cover the entire cross-sectional area. Additionally, 25 patients were excluded due to missing mGA data or blood samples. Thus, the present study included 115 patients (Figure 1). The mean age was 76.4 years (standard deviation: 5.0 years), $43 \%$ of the patients were women, and $16 \%, 20 \%$, and $64 \%$ had localized disease, locally advanced and metastatic disease, respectively. The most common diagnoses were colorectal cancer $(30 \%)$, lung cancer $(27 \%)$, other gastrointestinal cancers $(16 \%)$, and prostate cancer $(12 \%)$. According to the mGA, $56 \%$ of the patients were considered frail. The patients' baseline characteristics are shown in Table II. The GPS scores were 0 points for 61 patients $(53 \%), 1$ point for 41 patients $(36 \%)$, and 2 points for 13 patients (11\%). The mean CRP value was $23.7 \mathrm{mg} / 1$, with the quartiles defined as $<3 \mathrm{mg} / 1,3-7.9 \mathrm{mg} / 1,8.0-26.9 \mathrm{mg} / \mathrm{l}$, and $\geq 27.0 \mathrm{mg} / 1$.

Muscle measures and inflammation markers. According to the bivariate models, neither GPS nor CRP was associated with SMD (Table III). However, in the multiple models adjusting for age, gender, diagnosis, stage of disease, use of anti-inflammatory drugs and BMI, patients with a GPS=2 had significantly lower SMD compared to patients with GPS $=0$ ( $p=0.03)$ (Model 1, Table III), while there was still no association between CRP and SMD (Model 2, Table III).

For SMI, no significant association with GPS was found neither in the bivariate nor in multiple models (Table IV). There was also no significant association between CRP and SMI in the bivariate model. However, in the multiple linear regression model patients with CRP levels in the $4^{\text {th }}$ quartile had significantly lower SMI values compared to patients with CRP levels in the $1^{\text {st }}$ quartile ( $p=0.049$, Model 2, Table IV).

Muscle measures and frailty. According to the mGA results, frailty was not significantly associated with SMD or SMI in the bivariate or multiple linear regression models (Model 3 in Tables III and IV).

Muscle measures and other factors. In all multiple linear regression models, older age, higher BMI, lung cancer, or "other" cancer locations ( $v s$. colorectal cancer) were 
Table II. Patient characteristics.

\begin{tabular}{|c|c|c|c|c|c|c|c|c|}
\hline & \multicolumn{2}{|c|}{ All } & \multicolumn{2}{|c|}{ Eligible patients } & \multicolumn{2}{|c|}{ Non-frail } & \multicolumn{2}{|c|}{ Frail } \\
\hline & N (288) & $(\%)$ & N (115) & $(\%)$ & $\mathrm{N}(51)$ & $(\%)$ & N (64) & $(\%)$ \\
\hline Age, mean (SD) & 76.9 & (5.1) & 76.4 & $(5.0)$ & 76.5 & (5.6) & 76.3 & $(4.5)$ \\
\hline \multicolumn{9}{|l|}{ Gender } \\
\hline Female & 126 & (44) & 49 & (43) & 17 & (33) & 32 & (50) \\
\hline \multicolumn{9}{|l|}{ Cancer type } \\
\hline Prostate & 56 & (19) & 14 & (12) & 10 & (20) & 4 & (6) \\
\hline Other GI & 34 & (12) & 18 & (16) & 7 & (14) & 11 & (17) \\
\hline Lung & 59 & (21) & 31 & (27) & 11 & (22) & 20 & (31) \\
\hline Colorectal & 83 & (29) & 34 & (30) & 15 & (29) & 19 & (30) \\
\hline Other & 56 & (19) & 18 & (16) & 8 & (16) & 10 & (16) \\
\hline \multicolumn{9}{|l|}{ ECOG PS } \\
\hline 0 & 124 & (43) & 45 & (39) & 23 & $(45)$ & 22 & (34) \\
\hline 1 & 120 & (42) & 48 & (42) & 22 & (43) & 26 & (40) \\
\hline 2 & 37 & (13) & 20 & (17) & 6 & (12) & 14 & (22) \\
\hline 3 & 5 & (2) & 1 & (1) & - & & 1 & (2) \\
\hline 4 & 1 & (0) & 1 & (1) & - & & 1 & (2) \\
\hline Missing & 1 & & & & & & & \\
\hline \multicolumn{9}{|l|}{ Treatment } \\
\hline Curative* & 91 & (32) & 24 & (21) & 11 & (21) & 13 & $(20)$ \\
\hline Palliative chemotherapy & 126 & (44) & 67 & $(58)$ & 28 & $(55)$ & 39 & $(61)$ \\
\hline Other palliative systemic cancer treatment & 51 & (18) & 15 & (13) & 10 & $(20)$ & 5 & (8) \\
\hline Non-systemic palliative treatment** & 20 & (7) & 9 & $(8)$ & 2 & (4) & 7 & (11) \\
\hline \multicolumn{9}{|l|}{ Stage } \\
\hline Local & 73 & $(25)$ & 18 & (16) & 6 & $(12)$ & 12 & (1) \\
\hline Locally advanced & 55 & (19) & 23 & (20) & 11 & $(22)$ & 12 & (19) \\
\hline Metastatic & 160 & $(56)$ & 74 & (64) & 34 & $(67)$ & 40 & (62) \\
\hline BMI & & & 24.5 & (3.9) & 24.9 & (3.6) & 24.1 & $(4.1)$ \\
\hline
\end{tabular}

*Referred for neoadjuvant treatment, adjuvant treatment after curative surgery or curative radiotherapy; **Radiotherapy, palliative surgery, or palliative care. SD: Standard deviation; GI: gastrointestinal; ECOG PS: Eastern Cooperative Oncology Group performance status; BMI: body mass index.

significantly associated with lower SMD values. Relative to patients with metastatic disease, patients with locally advanced cancer had significantly higher SMD values (Table III). Older age, lower BMI, and female sex were significantly associated with lower SMI values.

\section{Discussion}

The present study assessed the associations between routinely available inflammatory markers, frailty, and CT-derived muscle measures in a cohort of older patients with cancer referred for systemic therapy for new or newly relapsed cancer. We found no associations between muscle measures and inflammation markers in bivariate analyses. When adjusting for other patient characteristics, we found that the patients with highest levels of inflammation (expressed by GPS 2), when compared to patients with lowest levels (GPS 0 ), had a lower SMD, and that patients with CRP levels in the highest quartile compared to those in the lowest quartile had a lower SMI. However, we did not observe any associations between muscle measures (SMI or SMD) and frailty.

Our results indicate a deleterious effect of inflammation on both muscle density and muscle mass in older patients with cancer, and are in accordance with previous studies on older non-cancer populations and patients with cancer in general ( 7 , 9). Inflammation is closely associated with poor outcomes in oncology (20, 23). However, we found no significant differences in SMD or SMI between patients with GPS scores of 1 and 0 points, or between the first, second and third CRP quartiles. These inconsistencies may have several explanations. Our patient cohort was heterogeneous; the patients differed in cancer diagnoses and stages of disease, and thereby in tumor burden and inflammatory load. Although broadly adjusted for in the analyses, these factors combined with a relatively small sample size may have obscured associations of moderate magnitudes. We also based our analyses on a single measurement of the biomarkers, and a range of conditions may lead to rapid increases in CRP, with correspondingly rapid decreases when the conditions are no 
Harneshaug et al: Inflammation, Frailty and Muscle Loss in Cancer Patients

Table III. Estimating the relationships between skeletal muscle density and the Glasgow Prognostic Score, C-reactive protein, and frailty.

\begin{tabular}{|c|c|c|c|c|c|c|c|c|}
\hline & \multicolumn{2}{|c|}{ Bivariate model } & \multicolumn{6}{|c|}{ Multiple linear regression models } \\
\hline & \multirow[b]{2}{*}{$\begin{array}{l}\text { Regr. coeff. } \\
(95 \% \mathrm{CI})\end{array}$} & \multirow[b]{2}{*}{$p$-Value } & \multicolumn{2}{|l|}{ Model 1} & \multicolumn{2}{|l|}{ Model 2} & \multicolumn{2}{|l|}{ Model 3} \\
\hline & & & $\begin{array}{l}\text { Regr. coeff. } \\
(95 \% \mathrm{CI})\end{array}$ & $p$-Value & $\begin{array}{l}\text { Regr. coeff. } \\
(95 \% \mathrm{CI})\end{array}$ & $p$-Value & $\begin{array}{l}\text { Regr. coeff. } \\
(95 \% \mathrm{CI})\end{array}$ & $p$-Value \\
\hline \multicolumn{9}{|l|}{$\begin{array}{l}\text { Glasgow } \\
\text { prognostic } \\
\text { score }\end{array}$} \\
\hline 0 & Reference & & Reference & & & & & \\
\hline 1 & $-1.84(-5.67,1.99)$ & 0.343 & $-0.86(-4.28,2.57)$ & 0.621 & & & & \\
\hline 2 & $-4.81(-10.23,0.61)$ & 0.081 & $-5.03(-9.56,-0.49)$ & 0.030 & & & & \\
\hline \multicolumn{9}{|l|}{$\begin{array}{l}\text { C-reactive } \\
\text { protein }\end{array}$} \\
\hline $\begin{array}{l}1^{\text {st }} \text { quartile } \\
(>3)\end{array}$ & Reference & & & & Reference & & & \\
\hline $\begin{array}{l}2^{\text {nd }} \text { quartile } \\
(3-8)\end{array}$ & $2.12(-3.07,7.30)$ & 0.948 & & & $-0.17(-4.86,4.53)$ & 0.944 & & \\
\hline $\begin{array}{l}3^{\text {rd }} \text { quartile } \\
(8-27)\end{array}$ & $-0.54(-5.58,4.50)$ & 0.586 & & & $-1.45(-6.24,3.34)$ & 0.549 & & \\
\hline $\begin{array}{l}4^{\text {th }} \text { quartile } \\
(>27)\end{array}$ & $-3.17(-8.30,1.95)$ & 0.322 & & & $-4.35(-9.71,1.00)$ & 0.110 & & \\
\hline \multicolumn{9}{|l|}{ Frail } \\
\hline No & Reference & & & & & & Reference & \\
\hline Yes & $0.36(-3.05,3.78)$ & 0.833 & & & & & $0.14(-2.78,3.07)$ & 0.923 \\
\hline Age & $-0.65(-0.97,-0.32)$ & $<0.001$ & $-0.74(-1.03,-0.45)$ & $<0.001$ & $-0.71(-1.01,-0.40)$ & $<0.001$ & $-0.73(-1.03,-0.43)$ & $<0.001$ \\
\hline Female sex & $-3.14(-6.73,0.45)$ & 0.086 & $-2.09(-5.16,0.99)$ & 0.181 & $-2.85(-6.19,0.49)$ & 0.094 & $-2.33(-5.51,0.86)$ & 0.150 \\
\hline \multicolumn{9}{|l|}{ Stage } \\
\hline Localized & $0.87(-3.76,5.50)$ & 0.710 & $1.96(-2.31,6.23)$ & 0.364 & $1.32(-3.20,5.83)$ & 0.564 & $2.88(-1.22,6.98)$ & 0.166 \\
\hline $\begin{array}{l}\text { Locally } \\
\text { advanced }\end{array}$ & $6.80(2.74,10.86)$ & 0.001 & $5.60(1.85,9.34)$ & 0.004 & $4.97(0.88,9.05)$ & 0.018 & $6.20(2.38,10.02)$ & 0.002 \\
\hline Metastatic & Reference & & Reference & & Reference & & Reference & \\
\hline \multicolumn{9}{|l|}{ Location } \\
\hline Colon & Reference & & Reference & & Reference & & Reference & \\
\hline Other GI & $-0.04(-5.31,5.23)$ & 0.988 & $-0.29(-5.25,4.67)$ & 0.907 & $-0.34(-5.68,5.01)$ & 0.899 & $-1.54(-6.47,3.39)$ & 0.536 \\
\hline Prostate & $-0.60(-6.10,4.90)$ & 0.828 & $2.07(-3.65,7.78)$ & 0.472 & $2.09(-5.59,9.77)$ & 0.560 & $1.62(-4.42,7.66)$ & 0.591 \\
\hline Lung & $-4.39(-8.89,0.12)$ & 0.056 & $-5.24(-10.02,-0.47)$ & 0.032 & $-6.10(-11.55,-0.65)$ & 0.030 & $-6.14(-11.05,-1.23)$ & 0.016 \\
\hline Other & $-7.70(-12.87,-2.53)$ & 0.004 & $-6.14(-10.81,-1.47)$ & 0.011 & $-5.88(-11.19,-0.57)$ & 0.031 & $-6.67(-11.51,-1.84)$ & 0.007 \\
\hline $\begin{array}{l}\text { Body mass } \\
\text { index }\end{array}$ & $-0.82(-1.28,-0.35)$ & 0.001 & $-0.89(-1.33,-0.46)$ & $<0.001$ & $-0.96(-1.43,-0.49)$ & $<0.001$ & $-0.85(-1.31,-0.39)$ & $<0.001$ \\
\hline $\begin{array}{l}\text { Anti- } \\
\text { inflammatory } \\
\text { medication }\end{array}$ & $-2.37(-6.96,2.23)$ & 0.309 & $-1.29(-5.11,2.52)$ & 0.502 & $-0.19(-4.31,3.93)$ & 0.928 & $-1.19(-5.19,2.81)$ & 0.555 \\
\hline
\end{tabular}

Regr. coeff.: Regression coefficient; CI: confidence interval; GI: gastrointestinal. Significant $p$-Values are shown in bold.

longer present (24). Furthermore, it may take some time for detectable loss of muscle mass to develop. Thus, longitudinal studies are advocated for future investigations into the association between these biomarkers and muscle loss.

In the last decade, the number of studies on muscle loss and sarcopenia in oncology has increased rapidly. However, most studies in this field have been retrospective, limiting the ability to fully describe the patient population characteristics (6). Few studies have hitherto investigated the relationship between muscle measures and frailty in older patients with cancer using
CT imaging for muscle quantification, so there is still a knowledge gap on how muscle loss and frailty are related to each other. Comparison between studies is hampered for several reasons. Different muscle groups have been chosen for assessment, and frailty has been related to continuous parameters for muscle measures as in the present study, or to sarcopenia/non-sarcopenia using various definitions of the term. Furthermore, several methods have been used to evaluate frailty. Our approach using mGA and a modification of the Balducci criteria is linked to the cumulative deficit 
in vivo $34: 3565-3572(2020)$

Table IV. Estimating the relationships between skeletal muscle index and the Glasgow Prognostic Score, C-reactive protein, and frailty.

\begin{tabular}{|c|c|c|c|c|c|c|c|c|}
\hline & \multicolumn{2}{|c|}{ Bivariate models } & \multicolumn{6}{|c|}{ Multiple linear regression models } \\
\hline & \multirow[b]{2}{*}{$\begin{array}{l}\text { Regr. coeff. } \\
(95 \% \mathrm{CI})\end{array}$} & \multirow[b]{2}{*}{$p$-Value } & \multicolumn{2}{|l|}{ Model 1} & \multicolumn{2}{|l|}{ Model 2} & \multicolumn{2}{|l|}{ Model 3} \\
\hline & & & $\begin{array}{l}\text { Regr. coeff. } \\
(95 \% \mathrm{CI})\end{array}$ & $p$-Value & $\begin{array}{l}\text { Regr. coeff. } \\
(95 \% \mathrm{CI})\end{array}$ & $p$-Value & $\begin{array}{l}\text { Regr. coeff. } \\
(95 \% \mathrm{CI})\end{array}$ & $p$-Value \\
\hline \multicolumn{9}{|l|}{ GPS } \\
\hline 0 & reference & & reference & & & & & \\
\hline 1 & $-0.81(-4.66,2.43)$ & 0.620 & $-0.31(-3.33,2.72)$ & 0.841 & & & & \\
\hline 2 & $-1.96(-6.54,2.63)$ & 0.399 & $-1.20(-5.33,2.29)$ & 0.564 & & & & \\
\hline \multicolumn{9}{|c|}{$1.80(1.07,2.00)$} \\
\hline $\begin{array}{l}1^{\text {st }} \text { quartile } \\
(<3)\end{array}$ & reference & & & & reference & & & \\
\hline $\begin{array}{l}2^{\text {nd }} \text { quartile } \\
(3-8)\end{array}$ & $-0.14(-4.44,4.16)$ & 0.948 & & & $-1.14(-4.84,2.56)$ & 0.542 & & \\
\hline $\begin{array}{l}3^{\text {rd }} \text { quartile } \\
(8-27)\end{array}$ & $1.16(-3.06,5.38)$ & 0.586 & & & $0.17(-3.45,3.79)$ & 0.927 & & \\
\hline $\begin{array}{l}4^{\text {th }} \text { quartile } \\
(>27)\end{array}$ & $-2.14(-6.41,2.13)$ & 0.322 & & & $-4.01(-8.01,-0.02)$ & 0.049 & & \\
\hline \multicolumn{9}{|l|}{ Frail } \\
\hline No & reference & & & & & & reference & \\
\hline Yes & $-1.22(-4.06,1.63)$ & 0.398 & & & & & $-0.08(-2.55,2.40)$ & 0.952 \\
\hline Age & $-0.47(-0.75,-0.19)$ & 0.001 & $-0.33(-0.59,-0.07)$ & 0.014 & $-0.33(-0.58,-0.07)$ & 0.012 & $-0.33(-0.59,-0.07)$ & 0.013 \\
\hline Female sex & $-6.95(-9.52,-4.37)$ & $<0.001$ & $-6.10(-8.80,-3.41)$ & $<0.001$ & $-6.77(-9.42,-4.12)$ & $<0.001$ & $-6.14(-8.83,-3.45)$ & $<0.001$ \\
\hline \multicolumn{9}{|c|}{ 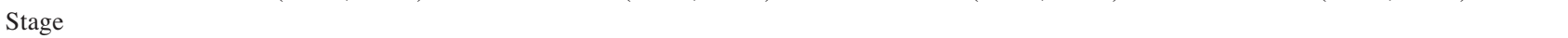 } \\
\hline Localized & $-0.66(-4.46,3.44)$ & 0.749 & $1.28(-2.55,5.10)$ & 0.509 & $0.16(-3.66,3.98)$ & 0.934 & $1.54(-2.04,5.13)$ & 0.395 \\
\hline $\begin{array}{l}\text { Locally } \\
\text { advanced }\end{array}$ & $-1.82(-5.40,1.77)$ & 0.317 & $1.57(-1.63,4.77)$ & 0.332 & $0.83(-2.34,3.99)$ & 0.606 & $1.71(-1.43,4.86)$ & 0.282 \\
\hline Metastatic & reference & & reference & & reference & & reference & \\
\hline \multicolumn{9}{|l|}{ Location } \\
\hline Colorectal & reference & & reference & & reference & & reference & \\
\hline Other GI & $-0.37(-4.75,4.01)$ & 0.867 & $-1.28(-5.45,2.89)$ & 0.543 & $-0.87(-4.85,3.12)$ & 0.667 & $-1.59(-5.50,2.32)$ & 0.422 \\
\hline Prostate & $2.42(-2.16,6.99)$ & 0.297 & $-0.25(-4.40,3.91)$ & 0.906 & $0.04(-4.07,4.15)$ & 0.984 & $-0.37(-4.53,3.79)$ & 0.859 \\
\hline Lung & $-0.15(-3.88,3.59)$ & 0.938 & $-0.19(-3.84,3.46)$ & 0.917 & $0.03(-3.45,3.51)$ & 0.986 & $-0.35(-3.73,3.02)$ & 0.836 \\
\hline Other & $-5.82(-10.12,-1.52)$ & 0.009 & $-4.00(-7.86,-0.15)$ & 0.042 & $-2.97(-6.79,0.86)$ & 0.127 & $-4.08(-7.85,-0.31)$ & 0.034 \\
\hline $\begin{array}{l}\text { Body mass } \\
\text { index }\end{array}$ & $0.58(0.21,0.95)$ & 0.003 & $0.48(0.13,0.84)$ & 0.009 & $0.40(0.04,0.75)$ & 0.028 & $0.49(0.13,0.85)$ & 0.008 \\
\hline $\begin{array}{l}\text { Anti- } \\
\text { inflammatory } \\
\text { medication }\end{array}$ & $3.31(-0.50,7.12)$ & 0.088 & $2.83(-0.48,6.14)$ & 0.092 & $3.74(0.43,7.05)$ & 0.027 & $2.86(-0.49,6.21)$ & 0.093 \\
\hline
\end{tabular}

Regr. coeff.: Regression coefficient; CI: confidence interval; GPS: Glasgow prognostic score; CRP: C-reactive protein; GI: gastrointestinal. Significant $p$-Values are shown in bold.

theory of frailty, a broad concept including accumulation of medical, physical, psychological, and cognitive deficits (25). Zwartz et al. (26) evaluated 112 patients with head and neck cancers using two screening tools for frailty, the Geriatric 8 (G8) and Groningen Frailty Index (GFI). They estimated SMI from cervical CT slices, and found that G8 scores were independently associated with sarcopenia, defined as SMI below a pre-defined threshold. Molina-Garrido et al. (27) evaluated 103 older patients who received chemotherapy and reported that sarcopenia was strongly correlated with the physical frailty phenotype (28), but not with frailty based on the Balducci criteria. In their study, sarcopenia was defined according to present consensus, which involves loss of muscle mass, strength, and function (3). Similar to our approach, Williams et al. (29) defined frailty according to a GA-based index, and used the third lumbar level for muscle assessment. They found that frailty was not associated with SMI among 162 patients with various cancer diagnoses. However, an increase in frailty prevalence with decreasing SMD was reported. Thus, our results are largely consistent with those obtained using a similar approach $(27,29)$. They are also in accordance with the general perceptions from outside oncology research. Although physical frailty measures and sarcopenia are strongly correlated as demonstrated by Molina- 
Garrido et al. (27), frailty and sarcopenia are assumed to be partly overlapping, but different entities (29).

Apart from the smaller sample size and cross-sectional design, the present study has some other limitations. First, it is debatable whether our frailty classification was too broad, as only one deficit was needed to be frail. However, similar to most studies in geriatric oncology (30), deficits were identified by a GA, and our classification was based on predefined criteria used by other researchers (30). Moreover, we have previously demonstrated that the older patients in our cohort who were identified as frail had poorer survival, physical function and quality of life compared to those who were non-frail, independent of cancer stage and diagnosis thus supporting the relevance of our categorization $(31,32)$. Second, the CT results we used for the body analyses were obtained during routine diagnostic imaging at different hospitals. Thus, a standardized approach in terms of CT machines and protocols was not possible. It is therefore reassuring that we, in accordance with present knowledge, demonstrated a consistent association between older age and lower SMI and SMD values, as well as an association between higher BMI and higher SMI values $(33,34)$. We also found that lower SMD values were associated with higher BMI values, which suggest that despite a general larger muscle mass with higher BMI, the muscle quality is poorer.

In conclusion, highest values of GPS and CRP might suggest the presence of loss of muscle mass and reduction of CT-based muscle density, respectively, in older patients with cancer when adjusted for other patient characteristics. However, these markers alone cannot be recommended as identifiers of muscular depletion. No association between muscle loss and frailty was found. Hence, our results indicate that CT-based muscle measures do not enable identification of frailty defined according to the broader concept of a geriatric assessment.

\section{Funding}

Publicly funded by Innlandet Hospital-Trust.

\section{Conflicts of Interest}

The Authors have no conflicts of interest to declare regarding this study.

\section{Authors' Contributions}

Study concepts: M Slaaen; Study design: M Slaaen; Data acquisition: L Kirkhus, M Harneshaug, M Slaaen; Data analysis and interpretation: Jurate Saltyte-Benth; M Harneshaug, L Kirkhus, M Slaaen, S Rostoft, BH Grønberg, S Bergh; Statistical analysis: Jurate Saltyte-Benth; Manuscript preparation: M Harneshaug, L Kirkhus, M Slaaen, Jurate Saltyte-Benth, S Rostoft, BH Grønberg, S Bergh; Manuscript editing: M Harneshaug, L Kirkhus, M Slaaen, S Rostoft, BH Grønberg, S Bergh, Jurate Saltyte-Benth; Manuscript review: L Kirkhus, M Harneshaug, M Slaaen, S Rostoft, BH Grønberg, S Bergh, Jurate Saltyte-Benth.

\section{Acknowledgements}

The Authors would like to thank the patients who accepted to participate in our research project, and the project nurses Signe Eldevik, Toril Nistad, Anne Mari Hanstad, Gunvor Hjelle, Bjørg Baklien, Gunhild Evenrud, Anne Glorvigen Hanstad, Astrid Rusten, Marit Opheim Auning, Eva Iren Haugen, Kathrine Engdal Horn and Unn-Cathrin Buvarp for their contribution in the assessment and follow-up of our patients. They would also like to express their gratitude to the local investigators Morten Brændengen, Oslo University Hospital and Olav Yri at Akershus University Hospital. Lastly, they want to thank Vicki Baracos and her colleagues at the Cross Cancer Institute, University of Alberta, Edmonton, for educating us in the use of the segmentation software.

\section{References}

1 Rolland Y, Czerwinski S, Abellan Van Kan G, Morley JE, Cesari M, Onder G, Woo J, Baumgartner R, Pillard F, Boirie Y, Chumlea WMC and Vellas B: Sarcopenia: its assessment, etiology, pathogenesis, consequences and future perspectives. J Nutr Health Aging 12(7): 433-450, 2008. PMID: 18615225. DOI: 10.1007/BF02982704

2 Cruz-Jentoft AJ and Sayer AA: Sarcopenia. Lancet 393(10191): 2636-2646, 2019. PMID: 31171417. DOI: 10.1016/S01406736(19)31138-9

3 Cruz-Jentoft AJ, Bahat G, Bauer J, Boirie Y, Bruyere O, Cederholm T, Cooper C, Landi FRolland Y, Sayer AA, Schneider SM, Sieber CC, Topinkova E, Vandewoude M, Visser M and Zamboni M: Sarcopenia: revised European consensus on definition and diagnosis. Age Ageing 48(1): 16-31, 2019. PMID: 30312372. DOI: 10.1093/ageing/afy 169

4 Zhang X, Wang C, Dou Q, Zhang W, Yang Y and Xie X: Sarcopenia as a predictor of all-cause mortality among older nursing home residents: a systematic review and meta-analysis. BMJ Open 8(11): e021252, 2018. PMID: 30420343. DOI: 10.1136/bmjopen-2017-021252

5 Shachar SS, Williams GR, Muss HB and Nishijima TF: Prognostic value of sarcopenia in adults with solid tumours: A meta-analysis and systematic review. Eur J Cancer 57: 58-67, 2016. PMID: 26882087. DOI: 10.1016/j.ejca.2015.12.030.

6 Williams GR, Rier HN, McDonald A and Shachar SS: Sarcopenia \& aging in cancer. J Geriatr Oncol 10(3): 374-377, 2019. PMID: 30343999. DOI: 10.1016/j.jgo.2018.10.009

7 Bano G, Trevisan C, Carraro S, Solmi M, Luchini C, Stubbs B, Manzato E, Sergi G and Verones N: Inflammation and sarcopenia: A systematic review and meta-analysis. Maturitas 96: 10-15, 2017. PMID: 28041587. DOI: 10.1016/j.maturitas.2016.11.006

8 Cesari M, Kritchevsky SB, Baumgartner RN, Atkinson HH, Penninx BW, Lenchik L, Palla SL, Ambrosius WT, Tracy RP and Pachor M: Sarcopenia, obesity, and inflammation-results from the Trial of Angiotensin Converting Enzyme Inhibition and Novel Cardiovascular Risk Factors study. Am J Clin Nutr 82(2): 428-434, 2005. PMID: 16087989. DOI: 10.1093./ajcn. 82.2 .428

9 Abbass T, Dolan RD, Laird BJ and McMillan DC: The relationship between imaging-based body composition analysis and the systemic inflammatory response in patients with cancer: A systematic review. Cancers 11(9), 2019. PMID: 31487957. DOI: $10.3390 /$ cancers 11091304 
10 Fearon K, Strasser F, Anker SD, Bosaeus I, Bruera E, Fainsinger RL, Jatoi A, Loprinzi C, MacDonald N, Mantovani G, Davis M, Muscaritoli M, Ottery F, Radbruch L, Ravasco P, Walsh D, Wilcock A, Kaasa S and Baracos VE: Definition and classification of cancer cachexia: an international consensus. Lancet Oncol 12(5): 489-495, 2011. PMID: 21296615. DOI: 10.1016/s1470-2045(10)70218-7

11 Baracos VE, Martin L, Korc M, Guttridge DC and Fearon KCH: Cancer-associated cachexia. Nat Rev Dis Primers 4: 17105, 2018. PMID: 29345251. DOI: 10.1038/nrdp.2017.105

12 Franceschi $\mathrm{C}$ and Campisi J: Chronic inflammation (inflammaging) and its potential contribution to age-associated diseases. J Gerontol A Biol Sci Med Sci 69(Suppl 1): S4-9, 2014. PMID: 24833586. DOI: $10.1093 /$ gerona/glu057

13 Cesari M, Prince M, Thiyagarajan JA, De Carvalho IA, Bernabei R, Chan P, Gutierrez-Robledo LM, Michel JP, Morley JE Ong P, Rodriguez Manas L, Sinclair A, Won CW, Beard J and Vellas B: Frailty: An emerging public health priority. J Am Med Dir Assoc 17(3): 188-192, 2016. PMID: 26805753. DOI: 10.1016/j. jamda.2015.12.016

14 Cesari M, Landi F, Vellas B, Bernabei R and Marzetti E: Sarcopenia and physical frailty: two sides of the same coin. Front Aging Neurosci 6: 192, 2014. PMID: 25120482. DOI: 10.3389/FNAGI.2014.00192

15 Harneshaug M, Kirkhus L, Benth JS, Gronberg BH, Bergh S, Whist JE, Rostoft S and Jordhoy MS: Screening for frailty among older patients with cancer using blood biomarkers of inflammation. J Geriatric Oncol, 2018. PMID: 30049582. DOI: 10.1016/j.jgo.2018.07.003

16 Wildiers H, Heeren P, Puts M, Topinkova E, Janssen-Heijnen ML, Extermann M, Falandry C, Artz A, Brain E, Colloca G, Flamaing J, Karnakis T, Kenis C, Audisio RA, Mohile S, Repetto L, Van Leewuen B, Milisen K and Hurria K: International Society of Geriatric Oncology consensus on geriatric assessment in older patients with cancer. J Clin Oncol 32(24): 2595-2603, 2014. PMID: 25071125. DOI: 10.1200/jco.2013.54.8347.

17 Balducci L and Extermann M: Management of the frail person with advanced cancer. Crit Rev Oncol Hematol 33(2): 143-148, 2000. PMID: 10737376. DOI: 10.1016/s1040-8428(99)00063-3.

18 Winograd CH, Gerety MB, Chung M, Goldstein MK, Dominguez F, Jr. and Vallone R: Screening for frailty: criteria and predictors of outcomes. J Am Geriatr Soc 39(8): 778-784, 1991. PMID: 1906492. DOI: 10.1111/j.1532-5415.1991.tb02700.x.

19 Savva GM, Donoghue OA, Horgan F, O'Regan C, Cronin H and Kenny RA: Using timed up-and-go to identify frail members of the older population. J Gerontol A Biol Sci Med Sci 68(4): 441446, 2013. PMID: 22987796. DOI: 10.1093/gerona/gls190

20 McMillan DC: The systemic inflammation-based Glasgow Prognostic Score: a decade of experience in patients with cancer. Cancer Treat Rev 39(5): 534-540, 2013. PMID: 22995477. DOI: 10.1016/j.ctrv.2012.08.003

21 Shen W, Punyanitya M, Wang Z, Gallagher D, St-Onge MP, Albu J, Heymsfield SB and Heshka S: Total body skeletal muscle and adipose tissue volumes: estimation from a single abdominal crosssectional image. J Appl Physiol 97(6): 2333-2338, 2004. PMID: 15310748. DOI: 10.1152/japplphysiol.00744.2004

22 Goodpaster BH, Carlson CL, Visser M, Kelley DE, Scherzinger A, Harris TB, Stamm E and Newmann AB: Attenuation of skeletal muscle and strength in the elderly: The Health ABC Study. J Appl Physiol 90(6): 2157-2165, 2001. PMID: 11356778. DOI: 10.1152/jappl.2001.90.6.2157
23 Tomita M, Maeda R, Ayabe T and Nakamura K: Prognostic impact of a novel tumor marker and inflammation index for patients with non-small-cell lung cancer. Anticancer Res 40(7): 4023-4027, 2020. PMID: 32620647. DOI: 10.21873/anticanres. 14397

24 Pepys MB and Hirschfield GM: C-reactive protein: a critical update. J Clin Invest 111(12): 1805-1812, 2003. PMID: 12813013. DOI: $10.1172 /$ jcl18921

25 Huisingh-Scheetz $\mathrm{M}$ and Walston J: How should older adults with cancer be evaluated for frailty? J Geriatr Oncol 8(1): 8-15, 2017. PMID: 27318797. DOI: 10.1016/j.jgo.2016.06.003

26 Zwart AT, van der Hoorn A, van Ooijen PMA, Steenbakkers R, de Bock GH and Halmos GB: CT-measured skeletal muscle mass used to assess frailty in patients with head and neck cancer. J Cachexia Sarcopenia Muscle 10(5): 1060-1069, 2019. PMID: 31134765. DOI: $10.1012 /$ jcsm. 12443

27 Molina-Garrido MJ, Guillen-Ponce C and Fernandez-Felix BM: Relationship between sarcopenia and frailty in a Spanish Cancer in the Elderly Unit: The ONCOSARCO Project. J Am Med Dir Assoc 17(8): 760-761, 2016. PMID: 27287932. DOI: 10.1016/ j.jamda.2016.04.025

28 Fried LP, Tangen CM, Walston J, Newman AB, Hirsch C, Gottdiener J, Seeman T, Tracy R, KOP WJ, Burke G and McBurnie MA: Frailty in older adults: evidence for a phenotype. J Gerontol A Biol Sci Med Sci 56(3): M146-56, 2001. PMID: 11253156. DOI: $10.1093 /$ gerona/56.3.m146.

29 Williams GR, Deal AM, Muss HB, Weinberg MS, Sanoff HK, Guerard EJ, Nyrop KA, Pergolotti M and Shachar SS: Frailty and skeletal muscle in older adults with cancer. J Geriatr Oncol 9(1): 68-73, 2018. PMID: 28844849. DOI: 10.1016/j.jgo.2017.08.002

30 Handforth C, Clegg A, Young C, Simpkins S, Seymour M, Selby $\mathrm{P}$ and Young J: The prevalence and outcomes of frailty in older cancer patients: a systematic review. Ann Oncol 26(6): 1091101, 2015. PMID: 25403592. DOI: 10.1093/annonc/mdu540

31 Kirkhus L, Saltyte Benth J, Rostoft S, Gronberg BH, Hjermstad MJ, Selbaek G, Wyller TB, Harneshaug M and Jordhoy MS: Geriatric assessment is superior to oncologists' clinical judgement in identifying frailty. Br J Cancer 117(4): 470-477, 2017. PMID: 28664916. DOI: $10.1038 / b j c .2017 .202$

32 Kirkhus L, Saltyte Benth J, Gronberg BH, Hjermstad MJ, Rostoft S, Harneshaug M, Selbaek G, Wyller TB and Jordhoy MS: Frailty identified by geriatric assessment is associated with poor functioning, high symptom burden and increased risk of physical decline in older cancer patients: Prospective observational study. Palliat Med 33(3): 312-322, 2019. PMID: 30712456. DOI: $10.1177 / 0269216319825972$

33 Thomas DR: Loss of skeletal muscle mass in aging: examining the relationship of starvation, sarcopenia and cachexia. Clin Nutr 26(4): 389-399, 2007. PMID: 17499396. DOI: 10.1016/j.clnu. 2007.03.008

34 Abramowitz MK, Hall CB, Amodu A, Sharma D, Androga L and Hawkins M: Muscle mass, BMI, and mortality among adults in the United States: A population-based cohort study. PloS One 13(4): e0194697, 2018. PMID: 29641540. DOI: 10.1371/journal. pone. 0194697

Received August 27, 2020

Revised September 20, 2020

Accepted September 21, 2020 